\title{
Lansley's NHS "reforms"
}

\author{
Something like this must never happen again
}

\author{
Alastair McLellan editor ${ }^{1}$, Jenni Middleton editor ${ }^{2}$, Fiona Godlee editor in chief $^{3}$ \\ ${ }^{1}$ Health Service Journal, London, UK; ${ }^{2}$ Nursing Times, London, UK; ${ }^{3} B M J$, London WC1H 9JR, UK
}

This editorial is jointly published in the BMJ, the HSJ, and the Nursing Times.

As the editors of the BMJ, Health Service Journal, and Nursing Times, we have divergent views on the government's NHS reforms and its beleaguered Health and Social Care Bill. But on one thing we are agreed-that the resulting upheaval has been unnecessary, poorly conceived, badly communicated, and a dangerous distraction at a time when the NHS is required to make unprecedented savings. Worse, it has destabilised and damaged one of this country's greatest achievements: a system that embodies social justice and has delivered widespread patient satisfaction, public support, and value for money. We must make sure that nothing like this ever happens again.

Health professional groups differ in their stance on whether to oppose the bill outright—as the BMA, the royal colleges of nursing and midwives, and the chartered physiotherapists have done- or whether to work with the government to try to improve the bill, as the NHS Confederation and the medical and surgical royal colleges have opted to do. But there can be no doubting the deep distress and lack of confidence in the government's plans among those who must deliver the service.

A chief executive of a primary care trust cluster admitted to one of us last week that the breakdown of the relationships between commissioners and hospital trusts caused by the structural mayhem had left him with no way of knowing for sure "if I've got another Mid Staffs on my doorstep." He was only reassured by the fact that "nothing much happens up here, so the local paper does a lot on health." One commentator told the $B M J$ that trusts are finding the current economic climate extremely tough and that "we've taken a running jump into the abyss." The changes have already laid waste huge amounts of management capacity and have undermined the ability of trusts to cope. It has been reported that previously solvent trusts are now facing serious financial problems.

The Department of Health has recently admitted that it still has "no clarity" over which new organisation will take on the functions performed by 11000 primary care trust staff, while the number and size of emerging clinical commissioning groups is a matter of increasing tension between general practitioners who want to maintain local control and the Department of
Health, which is worried about financial stability. The deadline for the new system to come into full effect is now only a little more than a year away.

The reforms did not have to result in this unholy mess. The Coalition Agreement released in the honeymoon period immediately after the election focused on clinical leadership and patient and public empowerment (www.cabinetoffice.gov. uk/news/coalition-documents). It was generally well received by those now at daggers drawn with the reforms.

But through a combination of poor political judgment and reluctance to engage with criticism, a set of (mostly) reasonable objectives morphed into an old fashioned top down reorganisation. This was the very thing the agreement had pledged to avoid. It also resulted in a bloated and opaque piece of legislation, the goals of which could have largely been achieved by other, more effective, means.

Despite calls from many quarters for the bill to be withdrawn, including the $B M J,{ }^{2}$ this is now unlikely to happen. So what will we be left with once the bill hauls its battered hulk across the Royal Assent finishing line? Firstly, despite the costly debate and scrutiny, we will still be in the dark about how much of the new system will work. Guidance and secondary legislation that will affect the function of key bodies_clinical commissioning groups, the health "sector regulator" Monitor, and the increasingly influential NHS Commissioning Board-are not due for many months.

Secondly, thanks to Lansley's initial tunnel vision, followed by the government's hasty compromises in the face of growing opposition, we will have an unstable system that is only partially fit for purpose. For it to work, the system will have to rely on a set of complex and sometimes conflicting relations between the Department of Health, the Commissioning Board, clinical commissioning groups, as yet undetermined clinical commissioning services, local authority health and wellbeing boards, and a host of other national, regional, and local actors. Care integration-now shoehorned into the legislation as a supposed antidote to the drive for increased competition between providers-is ill defined and lacks any meaningful incentives to encourage its adoption. 
It is possible to feel sorry for Lansley when-after years of being told that politicians should get out of the NHS-his proposals to loosen the health secretary's grip on the service were thrown back in his face. But those proposals were poorly thought through, and the government amendment restoring his responsibility for the NHS has failed to reassure some critics. This continuing uncertainty about exactly what his responsibilities will be has further dented confidence in the government's commitment to a publicly funded and comprehensive service.

Thirdly, because the proposed new system will have little resilience or cohesion, the next government will find it necessary to overhaul the NHS again. This is not good for anyone, least of all the front line staff. But ironically this may be Lansley's one great achievement: reforms designed and implemented so badly that another major NHS reform programme is guaranteed within five years.

What lessons can we learn from this debacle? Sustainable reform requires politicians to be clear about the problem they are trying to solve. A recurrent and justified criticism of these changes has been their failure to express a clear rationale. ${ }^{3} \mathrm{We}$ also need clarity on the methods proposed to solve the problem.

There has been a broad consensus among policy makers from all major parties for over 30 years about what is needed to deliver an effective and efficient health service. Cornerstones of this world view include a division between commissioners and health providers and the use of choice and competition to drive improvement. Yet relatively few healthcare staff share these views, and most of the public remain ignorant of the approach that is being taken and why. Both New Labour and the coalition failed to illuminate this debate-the Blairites because they were scared of frightening the party horses, the coalition through a failure to explain their proposals properly.

The NHS is far too important to be left at the mercy of ideological and incompetent intervention. Health policy has to respond rapidly to demographic and technological changes. But, rather than relying on policy makers to build brave new worlds in back rooms, we need a broad public debate on the principles that should underpin the NHS, how decisions on priorities should be made in a cash limited system, and what role clinicians and private sector organisations could and should play.

This debate will require restraint on behalf of all involved if it is to escape being characterised yet again by polarised views, (often disguised) vested interest, political point scoring, and conspiracy theories to the benefit of none. As part of this process, parliament should now establish an independently appointed standing commission, similar to the Sutherland and Dilnot commissions, to initiate a mature and informed national discussion on the future of our national health system.

The government's NHS reforms have proved divisive and destructive. They have slowed the improvement of NHS services and cost the UK money that it can ill afford. ${ }^{4}$ Let us try to salvage some good from this damaging upheaval and resolve never to repeat it.

Competing interests: All authors have completed the ICMJE uniform disclosure form at www.icmje.org/coi_disclosure.pdf (available on request from the corresponding author) and declare: no support from any organisation for the submitted work; no financial relationships with any organisations that might have an interest in the submitted work in the previous three years; the BMJ, HSJ, and Nursing Times all receive advertising and sponsorship from a wide range of public and private organisations that are affected by changes to the NHS.

Provenance and peer review: Commissioned; not externally peer reviewed.

Coombes R. How the health bill will change the NHS. BMJ 2012;344:e767 Delamothe T, Davies E, Godlee F. Bury the bill. BMJ 2011;342:d4050.

Appleby J. How satisfied are we with the NHS? BMJ 2011;342:d1836.

Walshe K. Reorganisation of the NHS in England. BMJ 2010:341:C3843.

@ BMJ Publishing Group Ltd 2012 